\title{
Glycaemic Index
}

\section{Relevance for health, dietary recommendations and food labelling ${ }^{\mathrm{a}}$}

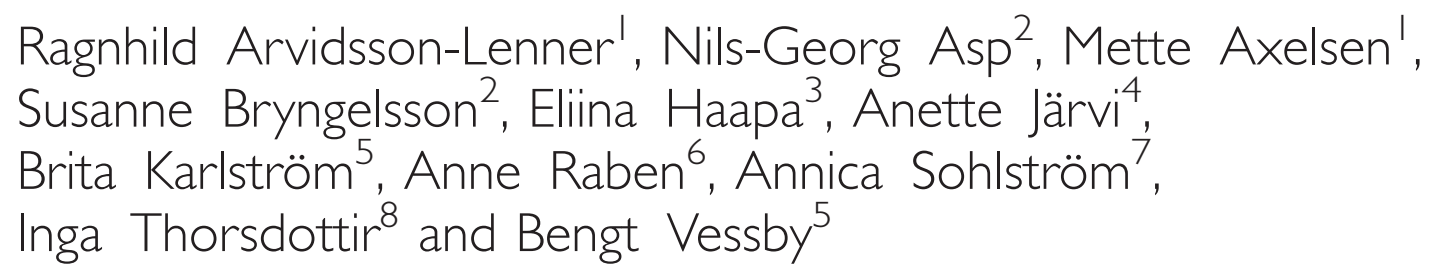

'Department of Clinical Nutrition, Sahlgrenska Academy at Göteborg University, Göteborg, Sweden; ${ }^{2}$ SNF Swedish Nutrition Foundation, Lund, Sweden; ${ }^{3}$ Diabetes Center, Finnish Diabetes Association, Tampere, Finland; ${ }^{4}$ Nestlé Sverige AB, Helsingborg, Sweden; ${ }^{5}$ Department of Public Health and Caring Sciences, Clinical Nutrition Research, Uppsala University, Uppsala, Sweden; 'Department of Human Nutrition, Centre for Advanced Food Studies, The Royal Veterinary \& Agricultural University, Copenhagen, Denmark; ${ }^{7}$ National Food Administration, Uppsala, Sweden and

${ }^{8}$ Unit for Nutrition Research, University Hospital, Reykjavik, Iceland

\section{Abstract}

The glycaemic index (GI) concept is based on the difference in blood glucose response after ingestion of the same amount of carbohydrates from different foods, and possible implications of these differences for health, performance and well-being. GI is defined as the incremental blood glucose area $(0-2 \mathrm{~h})$ following ingestion of $50 \mathrm{~g}$ of available carbohydrates in the test product as a percentage of the corresponding area following an equivalent amount of carbohydrate from a reference product. A high GI is generally accompanied by a high insulin response. The glycaemic load (GL) is the GI $\times$ the amount $(\mathrm{g})$ of carbohydrate in the food/100. Many factors affect the GI of foods, and GI values in published tables are indicative only, and cannot be applied directly to individual foods. Properly determined GI values for individual foods have been used successfully to predict the glycaemic response of a meal, while table values have not. An internationally recognised method for GI determination is available, and work is in progress to improve inter- and intra-laboratory performance. Some epidemiological studies and intervention studies indicate that low GI diets may favourably influence the risk of chronic diseases such as diabetes and coronary heart disease, although further well-controlled studies are needed for more definite conclusions. Low GI diets have been demonstrated to improve the blood glucose control, LDL-cholesterol and a risk factor for thrombosis in intervention studies with diabetes patients, but the effect in free-living conditions remains to be shown. The impact of GI in weight reduction and maintenance as well as exercise performance also needs further investigation. The GI concept should be applied only to foods providing at least $15 \mathrm{~g}$ and preferably $20 \mathrm{~g}$ of available carbohydrates per normal serving, and comparisons should be kept within the same food group. For healthy people, the significance of GI is still unclear and general labelling is therefore not recommended. If introduced, labelling should be product-specific and considered on a case-by-case basis.

Keywords: body weight; carbohydrates; disease risk; starch; sugars

\section{Introduction}

Dietary recommendations worldwide are concordant in recommending that carbohydrates should constitute 50-60 percent of the energy intake. This implies a more or less pronounced increase compared with current intakes in Western countries. The nutritional properties of the dietary carbohydrates then come into focus.

\footnotetext{
$\overline{{ }^{a} \text { Based }}$ on a meeting arranged by SNF Swedish Nutrition Foundation 22-23 August 2003.
}

A primary nutritional classification of carbohydrates is to differentiate between those digested and absorbed in the small intestine, providing carbohydrate to body cells (available carbohydrates, "glycaemic carbohydrates"), and those passing to the large intestine, providing substrate for the colonic microflora, i.e. dietary fibre (1).

The glycaemic index (GI) concept was introduced by Jenkins et al. in 1981 (2). GI is defined as the incremental blood glucose area $(0-2 \mathrm{~h})$ following ingestion of $50 \mathrm{~g}$ of available carbohydrates as a 
percentage of the corresponding area following an equivalent amount of carbohydrate from a standard reference product. Different research groups have used somewhat different blood sampling techniques (venous or capillary), times for calculating the glucose response area $(1.5-3 \mathrm{~h})$ and reference product (glucose or white bread). These methodological differences impair the comparison of data from different groups. The definition and methodology described in a recent FAO/WHO expert report, however, is now referred to as an international standard $(1,3)$. Calculation of incremental area under the postprandial glucose response curve (IAUC) according to this method is illustrated in Fig. 1. GI is calculated as $\left(\right.$ IAUC $\left._{\text {sample }} / \mathrm{IAUC}_{\text {standard }}\right) \times 100$.

The glycaemic response to a food, which in turn affects the insulin response, depends on the rate of gastric emptying, as well as on the rate of digestion and absorption of carbohydrates from the small intestine (4). People with diabetes have been advised to choose slowly absorbed carbohydrates. A low and prolonged glycaemic response helps these patients to improve their blood glucose control. "Slow carbohydrates" have often also been considered advantageous for healthy people to avoid an excessive insulin response and hypoglycaemia between meals. It was assumed that polysaccharides or "complex carbohydrates", i.e. starch, were "slow carbohydrates", whereas sugars (mono- and disaccharides) were considered "rapid". Later it has been demonstrated that many food factors other than the molecular size of the carbohydrate component are
Table I. Main food factors affecting the $\mathrm{Gl}$ of foods and meals

\begin{tabular}{|c|c|c|}
\hline Food factor & $\begin{array}{l}\text { Examples of } \\
\text { influencing } \\
\text { factors }\end{array}$ & Effect on GI \\
\hline \multicolumn{3}{|l|}{ Structure } \\
\hline Gross structure & $\begin{array}{l}\text { Grinding, } \\
\text { heat treatment }\end{array}$ & $\begin{array}{l}\text { Higher Gl when } \\
\text { homogenised }\end{array}$ \\
\hline $\begin{array}{l}\text { Cellular structure } \\
\text { (cell wall integrity) }\end{array}$ & Ripeness & $\begin{array}{l}\text { Higher GI with } \\
\text { increased ripeness }\end{array}$ \\
\hline \multicolumn{3}{|l|}{ Starch } \\
\hline $\begin{array}{l}\text { Granular structure } \\
\text { (intact or gelatinised) }\end{array}$ & Heat treatment & $\begin{array}{l}\text { Higher Gl when } \\
\text { gelatinised }\end{array}$ \\
\hline Amylose (unbranched) & $\begin{array}{l}\text { Genotype of raw } \\
\text { material }\end{array}$ & $\begin{array}{l}\text { Lower Gl compared to } \\
\text { amylopectin }\end{array}$ \\
\hline Amylopectin (branched) & $\begin{array}{l}\text { Genotype of raw } \\
\text { material }\end{array}$ & $\begin{array}{l}\text { Higher Gl compared to } \\
\text { amylose }\end{array}$ \\
\hline \multicolumn{3}{|l|}{ Other factors } \\
\hline $\begin{array}{l}\text { Gel-forming types of dietary } \\
\text { fibre }\end{array}$ & $\begin{array}{l}\text { Genotype of raw } \\
\text { material } \\
\text { Added fibres }\end{array}$ & Lowers GI \\
\hline Organic acids & $\begin{array}{l}\text { Fermentation } \\
\text { Added acids }\end{array}$ & Lowers GI \\
\hline Amylase inhibitor & Heat treatment & Lowers GI \\
\hline Fructose/glucose-ratio & $\begin{array}{l}\text { Genotype of raw } \\
\text { material } \\
\text { Type of added } \\
\text { sugars }\end{array}$ & $\begin{array}{l}\text { Lower GI with increased } \\
\text { ratio }\end{array}$ \\
\hline
\end{tabular}

important determinants of the glycaemic response, as reviewed by Björck et al. (5) and listed in Table 1. Therefore, different food products or meals with the same amount of carbohydrates show differences in glycaemic and insulinaemic responses.

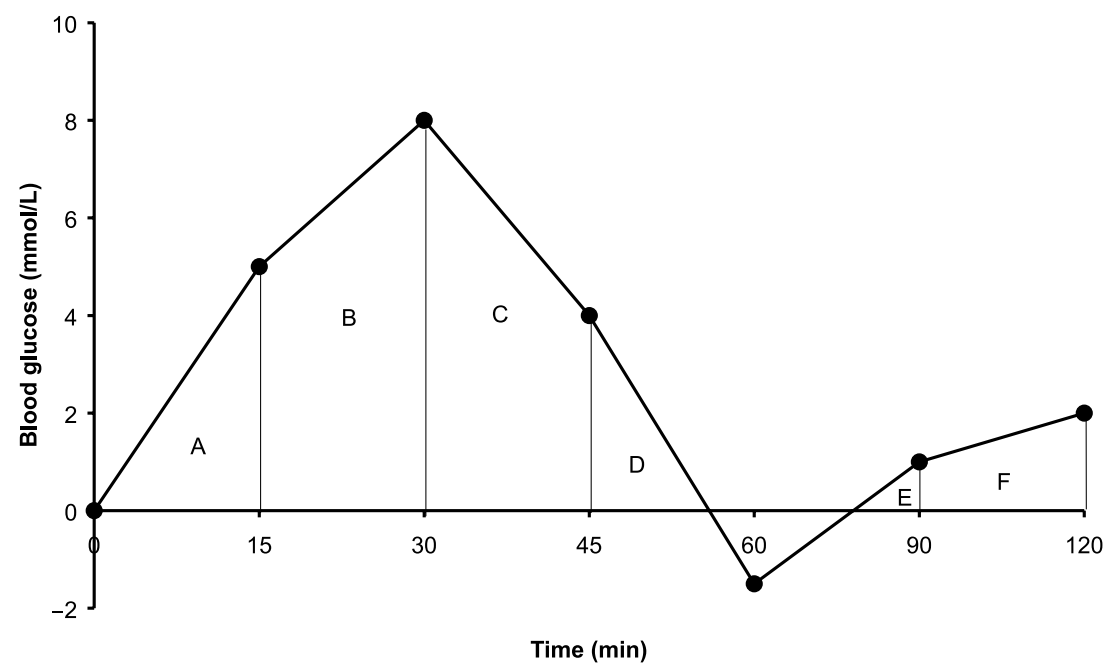

Fig. 1. The incremental area under the curve (IAUC) equals the sum of the areas A, B, C, D, E and F. Negative areas are not included. The figure is adapted from (1). 
The glycaemic response to the same food or meal may be influenced by the time, composition and GI of a previous meal. A prolonged glucose response after a breakfast meal has been demonstrated to improve glucose tolerance at lunch, denoted as the "second meal effect" (6-9). Overnight second meal effects have also been demonstrated $(8,10,11)$. Second-meal effects may reveal mechanisms for long-term effects of low GI foods, but the implications for health and clinical applications remain to be demonstrated. From a technical point of view regarding GI determinations, it is important to recognise that the second meal effect may influence the glycaemic response to a food. Probable mechanisms behind the second meal effect are briefly commented on in Box 1.

The present report focuses on the relevance and utility of the GI concept in relation to disease risk and weight management in healthy people. GI in relation to physical exercise is also briefly commented on (Box 2) and some important methodological considerations are summarised (Table 2). Finally, the application of GI in dietary recommendations and dietary counselling is considered, and in this context the relevance of and scientific support for introducing GI labelling on food products. Reference is made to the importance of GI for metabolic control in diabetes, although dietary counselling in diabetes is outside the scope of the report.

\section{GI tables and methodology}

GI values for more than 750 types of foods have been published in an international review of available GI values (12). The GI data in this table have been compiled over time in different laboratories.

\footnotetext{
Box I. THE SECOND MEAL EFFECT - PROBABLE MECHANISMS Breakfast to lunch

- Low-Gl breakfast attenuates the glycaemic response at lunch in both healthy and diabetic subjects (7-9).

- Some low-GI foods give a prolonged insulinaemic response, providing sustained, slightly elevated insulin levels at the time of the next meal (lunch).

- This may improve peripheral glucose uptake, i.e. glucose tolerance, as well as removal of circulating lipoproteins.

Overnight effects

- A late evening meal with slowly digested starch improves glucose tolerance at breakfast in type 2 diabetic patients $(10, \mathrm{I})$.

- A prolonged insulin response with concomitant prolonged nocturnal suppression of free fatty acids is a probable mechanism.

- In healthy individuals a similar effect was seen after an evening meal with low $\mathrm{Gl}$ and rich in dietary fibre (8).

- Colonic fermentation of dietary fibre, resulting in elevated serum levels of short-chain fatty acids, may reduce serum-free fatty acids and hepatic glucose output.
}

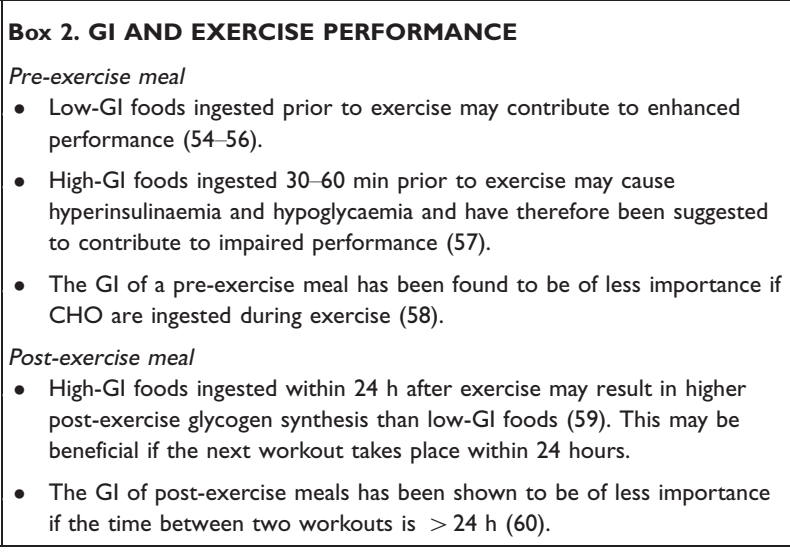

They are derived from products of different origin and brand, different types of test subjects, and somewhat different procedures for measuring and calculating GI have been used.

A considerable number of commercially available foods are included in the international review (12), but most foods represent the market in Australia, Canada, the US and the UK. From a Nordic perspective there is a lack of data for a variety of carbohydrate-rich foods (e.g. typical Scandinavian bread products, breakfast cereals, gruels, porridges, certain vegetables and legume products, such as pea soup and pickled brown beans). It should also be noted that an important number of the low-GI products included in the table are "experimental products" designed to answer specific academic questions regarding e.g. the impact of various food factors on GI, and many of the low-GI cereal products in the table are not available on the market. As shown in Table 3, there can be a considerable variation of reported GI values for one type of food, for example long-grain/ parboiled rice $(\mathrm{GI}=38-72)$ and boiled potatoes $(\mathrm{GI}=24-101)$. Furthermore, the GI value of some items, e.g. jasmine rice, is based on one study only. Thus, a GI value obtained from a GI table should not be seen as an exact value but may be useful as an indication of the expected glycaemic response.

General principles for determination and calculation of GI have been described in the FAO/WHO report "Carbohydrates in Human Nutrition" (1). In a recent inter-laboratory study, the GI of 5 foods was measured in 7 different laboratories around the world using a local white bread as a standard (3). Mean GI values for the different foods did not differ considerably between laboratories, although individual determinations for the same food varied 
Table 2. Important methodological considerations

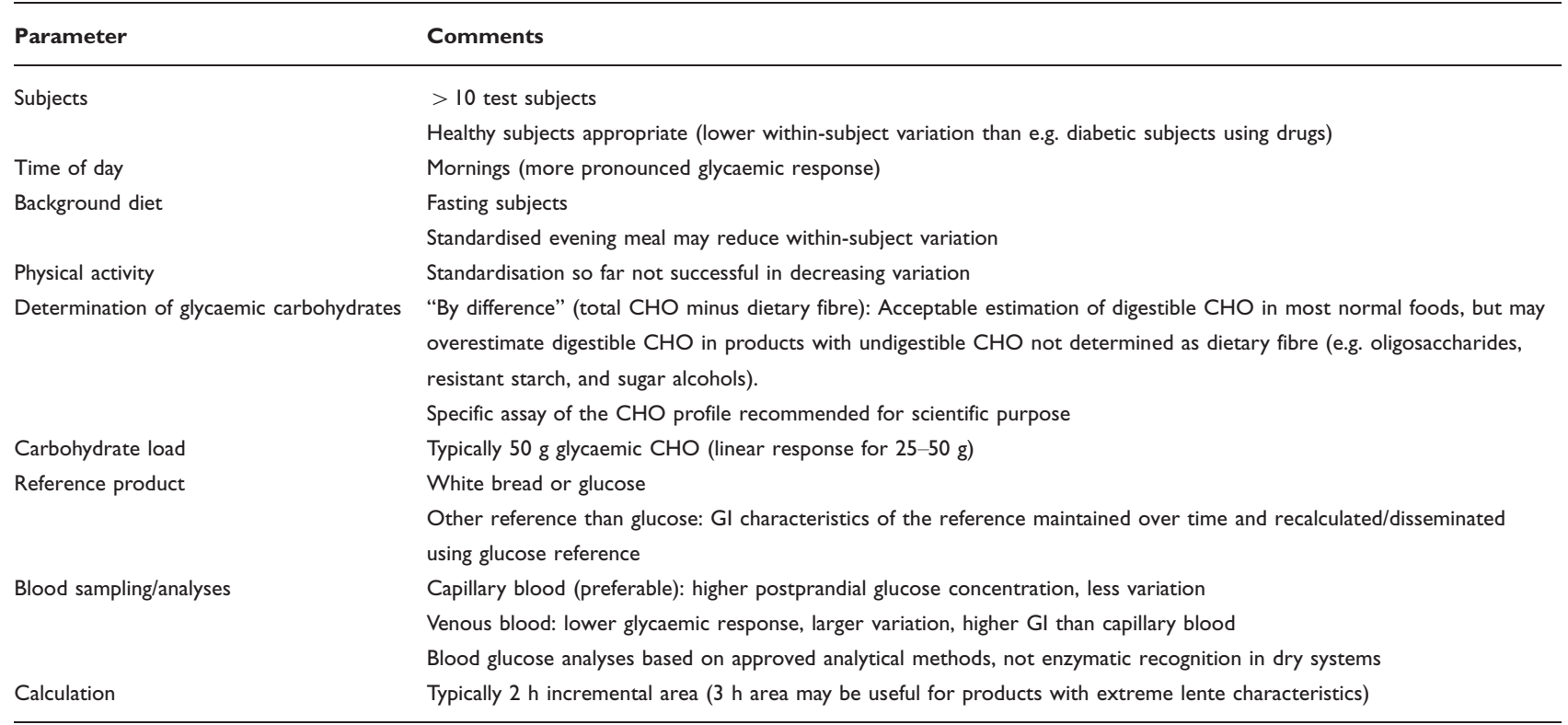

$\mathrm{CHO}=$ carbohydrates.

by 17 to 34 GI units. Thus, it is essential to accomplish further method standardisation on an international level. A major reason for variation in the GI determination was a random within-subject variation. It is outside the scope of the present paper to review the multitude of factors that may be important in relation to GI determination and calculation. An expert group within ILSI-Europe is currently working with this issue. Some methodological aspects are summarised in Table 2.

Several food factors (Table 1) and processing and cooking conditions (13) affect GI. This is the basis for designing foods with specific GI, but differences in GI due to these factors are also perceived as a particular shortcoming of the concept per se. This problem is, however, shared with several other nutrients for which the content and bioavailability may be affected by processing and/or storage. To address this problem, and increase the utility of published data, relevant product characteristics need to be reported along with the GI in food tables. Furthermore, the content of energy, carbohydrate, fat and protein, as well as portion size, are important factors, which should be considered in dietary counselling and application of GI in practice.

Table 3. Glycaemic index, glycaemic load and energy per serving of selected foods

\begin{tabular}{|c|c|c|c|c|c|c|}
\hline \multirow[t]{2}{*}{ Food' } & \multirow[t]{2}{*}{$\mathbf{n}$} & \multirow[t]{2}{*}{$\mathrm{GI}^{2}($ glucose $=100)$} & \multirow[t]{2}{*}{ Serving size ${ }^{3}(g)$} & \multicolumn{3}{|c|}{ per serving } \\
\hline & & & & $\mathrm{CHO}(\mathrm{g})$ & $\mathbf{G L}$ & $\begin{array}{l}\text { Energy } \\
\text { (kcal) }\end{array}$ \\
\hline Rice long-grain/parboiled $(277,230)$ & 23 & $51(38-72)$ & 175 & 50 & 26 & 200 \\
\hline Rice jasmine (300) & I & 109 & 175 & 52 & 57 & 200 \\
\hline Spaghetti, white $(532,535)$ & II & $40(32-47)$ & 225 & 56 & 22 & 286 \\
\hline Spaghetti, white $(532,535)$ & 11 & $40(32-47)$ & $180^{2}$ & 45 & 18 & 236 \\
\hline Potato, baked $(602,603)$ & 5 & $80(56-111)$ & 160 & 29 & 23 & 136 \\
\hline Potato, boiled $(604,605)$ & 12 & $65(24-101)$ & 150 & 29 & 19 & 130 \\
\hline
\end{tabular}

${ }^{1}$ Numbers refer to the numbers used in (12).

${ }^{2}$ According to (12).

${ }^{3}$ Typical Scandinavian serving sizes according to (6I).

$\mathrm{CHO}=$ carbohydrates. 
Given the definition of GI, the concept is useful only for foods that provide substantial amounts of available carbohydrates. GI values for low carbohydrate foods, e.g. vegetables or foods mainly containing fat and protein, are difficult to determine and may be misleading when used in practice. It is suggested, therefore, that the GI concept is applied only to foods providing at least $15 \mathrm{~g}$ and preferably $20 \mathrm{~g}$ glycaemic carbohydrates per portion, i.e. products such as bread, cereals, pasta, rice and potatoes.

\section{Glycaemic load}

In practice, the actual carbohydrate load from a normal portion size varies considerably between food products. In order to address this problem, the concept of glycaemic load (GL) was introduced (14, 15), representing both the quality and the quantity of the carbohydrates in a food or a meal. GL allows comparisons of the likely glycaemic effect of realistic portions of different foods, calculated as the amount of carbohydrate in one serving times the GI of the food (i.e. $\mathrm{GL}=\mathrm{g}$ carbohydrate $\times \mathrm{GI} / 100$ ). For example, spaghetti has a lower GI than boiled potatoes, but normal portion sizes of spaghetti are commonly larger than portions of potatoes. Therefore, GL may or may not differ between these two carbohydrate sources, depending on the applicable GI values and portion sizes, as illustrated in Table 3.

\section{Mixed meals}

One important point when using the GI concept is its applicability to mixed meals. Some studies using measured GI values of the key foods responsible for differences in GI have shown that the GI of a composite meal can be predicted from the GI values of the different carbohydrate-rich foods included (16-20), as exemplified in Table 4. However, other studies have concluded that differences in GI between foods are diminished when incorporated in composite meals $(21,22)$. In one study, using GI values of the included food items from the international table (Foster-Powell 2002) and measuring the GI value of the final meal according to WHO (1), no correlation between the measured and calculated values of 14 European breakfast meals was found (23). In addition to the considerable range of values for the same food making it difficult to choose the relevant one, different countries might have different names for the same foods or the same name for foods with different compositions.

Fat and protein may influence gastric emptying and insulin secretion, but effects on GI are generally not seen unless relatively large amounts (about $30 \mathrm{~g}$ of protein and $50 \mathrm{~g}$ of fat per $50 \mathrm{~g}$ carbohydrates) are added (24). An exception is milk protein, which increases the insulin response. Although addition of fat and protein to a meal containing carbohydrates may result in a lower glucose response, the relative difference between starch-rich foods with different GI values remains (25).

\section{Risk of diabetes and coronary heart disease} Hypotheses regarding protective effects of low-GI diets against chronic disease such as diabetes and coronary heart disease have been tested in epidemiological observational studies. Short- to mediumterm intervention studies regarding risk factors have been performed mainly in type 2 diabetes patients.

\section{Observational studies}

A number of epidemiological studies have correlated the GL or GI to disease risk. A main shortcoming of some of these studies is the use of data from a dietary assessment method not geared to the study of GI and GL. Another shortcoming, shared with epidemiological studies in general, is a

Table 4. Principle for calculation of the glycaemic index of meals

\begin{tabular}{|c|c|c|c|c|c|c|}
\hline Food & $\begin{array}{l}\text { CHO per } 100 \mathrm{~g}^{\prime} \\
(\mathrm{g})\end{array}$ & $\begin{array}{l}\text { Portion size } \\
\text { (g) }\end{array}$ & $\begin{array}{l}\text { CHO per portion } \\
\text { (g) }\end{array}$ & $\begin{array}{l}\text { Proportion of total } \mathrm{CHO} \\
(c=a / b)\end{array}$ & $\begin{array}{l}\text { Food } \mathbf{G I}^{2} \\
\text { (d) }\end{array}$ & $\begin{array}{l}\text { Meal GI } \\
\mathbf{e}=\Sigma(\mathbf{c} \times \mathbf{d})\end{array}$ \\
\hline Yoghurt & 4.9 & 250 & (a) 12.3 & (c) 0.24 & (d) 51 & \\
\hline Cornflakes & 78.6 & 25 & (a) 19.7 & (c) 0.38 & (d) 116 & \\
\hline White bread & 48.8 & 40 & (a) 19.5 & (c) 0.38 & (d) 101 & \\
\hline Total & & & (b) 51.5 & & & (e) 94 \\
\hline
\end{tabular}

\footnotetext{
I According to (62).

${ }^{2}$ According to (12).

$\mathrm{CHO}=$ carbohydrates .
} 
lack of relevant analytical data for foods, in this case the shortage of standardised GI values relevant for foods consumed by the population under investigation.

Early studies indicated that there is no evident relation between intake of sugar and development of type 2 diabetes (26). In agreement with this, the Dutch Zutphen Study showed no relationship between intake of "simple" or "complex" carbohydrates and risk of diabetes in elderly (64-85-yearold) men and women during a four-year follow-up (27). On the other hand, a direct relation between increased intake of glucose and fructose ("simple carbohydrates") and the risk of diabetes was showed in the Iowa Women's Health Study (28). In the same study, an inverse relation between whole grain consumption and risk for diabetes was showed, but no relation between GI and diabetes risk. Thus, other factors in whole grains, or factors associated with whole grain consumption, may contribute to the preventive effect.

In the Nurses' Health Study an increased risk of diabetes was positively related to increased GI or GL during a six-year follow-up (15). The combination of a low intake of cereal dietary fibre and high GL was associated with a doubled risk of women developing diabetes. In a recently published followup (16 years) of the same study the relation between high GL and risk of diabetes was confirmed (29). Furthermore, in the Health Professionals' Followup Study from the same group, a similar relation between high GL and risk of developing diabetes was found in men (14). Also in this study the disease risk was further increased by a low intake of dietary fibre from cereals.

In a 10-year follow-up of the Nurses' Health Study, a high dietary GL from rapidly digested and absorbed carbohydrates was related to an increased risk of coronary heart disease in overweight $(B M I \geq 23)$ women (30). An increased risk of developing CHD due to a high GL diet was supported by the observation of a negative influence on the lipid risk profile (31). In fact, several observational studies show a negative correlation between GL and HDL-cholesterol, i.e. low GL was associated with increased HDL (31-33). In contrast, from the Zutphen Study with elderly men and women, no significant relation between GI and CHD was found after correction for other risk factors and dietary factors (34). Nor were any significant relations found between GI and blood lipid values (total cholesterol, HDL and triglycerides) in that study.

A weakness in the observational studies regarding the relations between GI and GL and risk of diabetes and CHD is that most positive studies originate from one research group only $(14,15,29$, 31 ), using a certain type of food frequency questionnaires for GI and GL calculations. To provide convincing evidence, similar results should be published from other research groups, preferably from outside the US, using adequate dietary assessment methods. More studies on men are also needed.

\section{Intervention studies}

Mechanisms behind a possible protective effect of a low GI diet against diabetes and CHD might include effects on total and LDL cholesterol, insulin levels and insulin sensitivity, coagulation factors and protein glycation. Up to now intervention studies have been performed mainly in diabetic (4, 17, 35), hyperlipidaemic (36) and hyperinsulinaemic patients $(37,38)$. A recent meta-analysis demonstrates a small but clinically useful effect on medium-term glycaemic control, with an average reduction in $\mathrm{HbAlc}$ by $0.43 \%$ points, on a lowcompared to high-GI diet in diabetic subjects (39). However, in a few studies on insulin sensitivity (a strong risk factor for development of type 2 diabetes) with validated methods, there were no significant differences between the treatment periods $(17,38)$. Controlled dietary intervention studies have suggested beneficial effects of low-GI food on total and LDL-cholesterol $(4,17,35,40)$. In one well-controlled study in type 2 diabetic subjects (17) there was a significant reduction of LDL cholesterol, and a reduction of PAI-1 on the low-GI diet, suggesting an improvement of the lipid profile and the fibrinolytic capacity. In non-diabetic subjects there is not yet any consistent data showing risk factor reductions on a low- compared with a highGI diet. More well-controlled studies over longer periods are needed, in both diabetic and nondiabetic subjects.

\section{Long-term effects}

A most relevant question is whether low-GI foods incorporated in the diet have a sustained long-term effect in improving metabolic control. However, long-term effects of GI are not easily studied because of the limited availability of commercial low-GI 
foods. Furthermore, most protocols used for collecting dietary data are poorly designed to identify the GI of the diet, and most long-term intervention studies with free-living persons comparing diets with different GI values lack a careful description of the details of the diet. The volunteers in the studies may only have been encouraged to change their major source of carbohydrates to either low- or high-GI food, without any further guidance (41). It is likely that also other macronutrients, e.g. dietary fibre and fat, will be changed if no specific dietary advice or menus are given to the volunteers, and this might influence the results. Such manipulations can only be expected to cause small differences between high-GI and low-GI diets $(41,42)$ and therefore do not fully explore differences between high- and low-GI diets. Furthermore, many studies lack or have questionable definitions of high- versus low-GI foods or diets. One important point is whether carbohydrates that are rapidly absorbed - such as fructose, sucrose and lactose - but have a low or moderate GI due to their chemical composition should be included in a lowGI diet or not.

\section{Weight management}

There are several mechanisms by which low GI foods and diets could be advantageous in relation to weight management and obesity. A prolonged blood glucose response could e.g. be expected to favour satiety, possibly related to a more distal absorption. Furthermore, many carbohydrate-rich foods with a low GI also have a high fibre content (e.g. beans) and thereby a more pronounced satiating effect. However, in practice many factors have to be considered and related to possible effects of the GI on body weight. Some low-GI foods such as pasta and parboiled rice may in some instances be consumed in larger quantities and therefore provide more calories than high-GI alternatives such as boiled potatoes (Table 3 ).

Raben et al. recently made a systematic review of available studies on GI in relation to weight management and obesity (43). From 31 short-term $(<1$ d) intervention studies on satiety/hunger/ appetite, low-GI foods were associated with greater satiety or reduced hunger in 15 of the studies only, and reduced ad libitum food intake in 7 studies. Both high- and low-GI carbohydrates have been shown to have an impact on satiety, but their effects have different time courses (44). High-GI carbohydrates are associated with a reduction in appetite and food intake in the short term (e.g. one hour), whereas the satiating effects of lower-GI carbohydrates appear to be delayed (e.g. 2 to 3 hours).

The above-mentioned review also included 20 long-term $(\geq 6 \mathrm{~d})$ intervention studies on GI in relation to body weight. Since then, data from 4 more studies have become available (40, 45-47). However, of the 24 studies only 11 used test and control diets with comparable macronutrient composition, which is an appropriate design for specifically studying the effect of dietary GI on body weight. The mean weight change in the 11 studies was a reduction of 3.42 and $2.84 \mathrm{~kg}$ on the low-GI and high-GI diet, respectively. Only 4 studies allowed ad libitum intake (2-10 weeks duration), and in these the average weight change was a reduction of 0.55 and $0.50 \mathrm{~kg}$ on the low- and high-GI diet, respectively. Taken together, the available studies with appropriate design therefore do not indicate any major effect of GI on body weight. In contrast, another recent review concluded that obese patients should be counselled to follow a lowGI diet (48). This review did not, however, include all available studies in a systematic manner. Obviously, more long-term studies with an appropriate design, e.g. keeping all macronutrients, energy density and dietary fibre similar and only manipulating the GI, are needed to judge the usefulness of the GI concept for weight management.

\section{Dietary recommendations and practical implications}

\section{International dietary guidelines}

Current international dietary guidelines are concordant in stressing the importance of a diet rich in fruits and vegetables, pulses and whole-grain cereals, but vary regarding the importance of GI. In the latest recommendations on carbohydrate intake from FAO/WHO the choice of low-GI foods in persons with hyperlipidaemia and obesity as well as healthy persons is recommended (1). In the most recent WHO report, "Diet nutrition and the prevention of chronic diseases", the strength of evidence that low-GI foods reduce the risk of obesity and diabetes is graded as "possible" (49). However, in the recent Food and Nutrition Board (FNB) macronutrient report it is concluded that: "Due to lack of sufficient evidence on the prevention of chronic diseases in generally healthy individuals, no recommendations based on glycaemic index are 
made" (50). Regarding dietary guidelines for patients with diabetes, the "Recommendations for the Nutritional Management of Patients with Diabetes" by The Diabetes and Nutrition Study Group (DNSG) of the European Association for the Study of Diabetes (EASD) (51) state that carbohydratecontaining foods that are rich in dietary fibre or have a low GI are especially recommended.

\section{Main carbohydrate sources}

The most important carbohydrate-rich foods in the Nordic countries, for which GI is relevant, are products based on cereals and potatoes. Many bread, breakfast cereals and potato products are found in the upper GI range, whereas e.g. pasta, parboiled rice and sourdough bread are found in the lower range (12). Most main carbohydrate sources in the Nordic diets, as well as minor sources such as beans and lentils, contribute to the intake of valuable nutrients, which have to be considered in addition to their GI. Different kinds of beans and lentils, belonging to the foods with the lowest GI values, contribute dietary fibre and other valuable nutrients, so increased consumption of these should be encouraged.

\section{Fruits and vegetables}

According to GI tables, most fruits and vegetables have medium or high GI values but their carbohydrate density is rather low. Consequently, the GI concept should not be applied to this category of food. Fruits and vegetables provide dietary fibre, vitamins and minerals, and less energy than many other foods and should, thus, be promoted as a part of a healthy diet.

\section{Sugars}

The GI values of common sugars increase in the following order: fructose $<$ lactose (glucose + galactose $)<$ sucrose $($ glucose + fructose $)<$ glucose The application of GI to products mainly consisting of sugars, e.g. confectionary or carbonated drinks, however, is highly questionable in view of the high energy content/density and lack of micronutrients, which are reasons for limiting the consumption of these products.

\section{Milk products}

The GI of milk and other dairy products is low or medium-high. However, like fruits and vegetables, milk products are generally rather low in carbohy- drates, with the exception of sweetened yoghurts, milk-shakes etc. The GI concept is therefore generally not applicable to milk products. Furthermore, an inconsistency between the glycaemic and insulinaemic responses has been shown for both regular and fermented milk products, both resulting in high postprandial insulinaemic responses (52). Also when included in a low-GI pasta meal, milk evokes a high insulin response (53). The importance of this insulinotropic effect of milk remains to be elucidated.

\section{Labelling}

A possibility to label foods with GI would serve interested consumers and may be an incentive for producers to develop products suitable for low-GI labelling. GI values of certain products, e.g. bread and breakfast cereals, may vary widely. Low-GI alternatives and tools to identify them may be helpful for diabetic patients. However, for healthy people, the significance of GI is still unclear, and it cannot be judged at present to what extent labelling may contribute to overall public health.

Special consideration is needed if foods are labelled with GI values as an aspect of nutrition information. There are three main prerequisites for justification of such labelling: 1 . GI has to be assessed for the specific food product to be labelled, by an experienced laboratory/clinic. 2. GI is only appropriate to use for carbohydrate-rich foods (e.g. bread, breakfast cereals, pasta, rice and potatoes, providing at least $15 \mathrm{~g}$ and preferably $20 \mathrm{~g}$ carbohydrate per normal serving). 3. Comparison of GI should be limited to foods within the same food group. In Sweden, GI might so far be regarded as a "product-specific physiological claim" and handled on a case-by-case basis within the code of conduct on health claims.

\section{Summary and conclusions}

Some epidemiological studies suggest that low-GI foods, or low-GL diets, might contribute to a reduced risk of cardiovascular disease and type 2 diabetes, but consensus is not reached. Regarding body weight control, more controlled studies are needed to provide conclusive evidence for the benefits of low-GI foods.

To draw conclusions regarding the overall role of GI for healthy people, well-designed long-term studies (preferably $>6$ months) are needed. However, the present shortage of low-GI carbohydrate foods on the market and the intrinsic connection 
between low GI and high fibre content hampers the optimal design of such studies. The studies should be conducted with an ad libitum design and ideally only glycaemic index (i.e. not protein, fat, carbohydrate, dietary fibre or energy density) should be manipulated. Appropriate methods should be used to document dietary habits and compliance.

The GI concept is relevant for carbohydrate-rich foods only, i.e. foods providing at least $15 \mathrm{~g}$ and preferably $20 \mathrm{~g}$ of glycaemic carbohydrates per portion (i.e. products such as bread, cereals, rice, pasta and potatoes) and comparison should be limited to foods within the same product group.

GI values for food tables should be determined using an internationally standardised GI methodology. The accuracy of the proposed methodology should be verified in inter-laboratory tests as for other analytical methods in food analysis. It is essential that GI determinations are based on appropriate food analyses.

The GI concept should not be used in isolation. GI values in tables should therefore be accompanied by other relevant product characteristics, e.g. content of available carbohydrates, enabling the calculation of GL and the content of macronutrients and dietary fibre. If such data are present the GI tables may be a useful tool for dietary counselling to diabetic patients. Furthermore, the effects of the different components in the food on e.g. blood lipids and blood pressure, should be considered. Dietary recommendations, including the possible use of GI, have to be presented in a balanced way.

Labelling of foods with GI would be helpful for persons with diabetes, but the usefulness for healthy people is still unclear. Awaiting further intervention studies, international method standardisation and authorisation of laboratories, as well as forthcoming EU regulation of nutrition and health claims on foods, it is regarded as premature to introduce GI labelling generally.

\section{References}

1. FAO Food and Nutrition Paper 66: Carbohydrates in human nutrition. Report of a joint FAO/ WHO Expert Consultation, Rome; 1998.

2. Jenkins DJA, Wolever TMS, Taylor RH, Barker H, Fielden H, Baldwin JM, et al. Glycaemic index of foods: a physiological basis for carbohydrate exchange. Am J Clin Nutr 1981; 34: 362-6.
3. Wolever TMS, Vorster HH, Björck I, Brand-Miller J, Brighenti F, Mann JI, et al. Determination of the glycemic index of foods: interlaboratory study. Eur J Clin Nutr 2003; 57: 475-82.

4. Jenkins DJA, Wolever TMS, Collier GR, Ocana A, Rao AV, Buckley G, et al. Metabolic effects of a lowglycemic-index diet. Am J Clin Nutr 1987; 46: 968-75.

5. Björk I, Liljeberg H, Östman E. Low glycaemic-index foods. Br J Nutr 2000; 83(Suppl 1): 149-55.

6. Jenkins DJA, Wolever TMS, Taylor R, Griffiths C, Krzeminska K, Lawrie J, et al. Slow release dietary carbohydrate improves second meal tolerance. Am J Clin Nutr 1982; 35: 1339-46.

7. Wolever TMS, Jenkins DJ, Ocana A, Rao V, Collier G. Second-meal effect: low-glycemic-index foods eaten at dinner improve subsequent breakfast glycemic response. Am J Clin Nutr 1988; 48: 1041-7.

8. Björck I, Elmståhl HL. The glycaemic index: importance of dietary fibre and other food properties. Proc Nutr Soc 2003; 62: 201-6.

9. Liljeberg HGM, ̊kerberg AKE, Björck IME. Effect of the glycemic index and content of indigestible carbohydrates of cereal-based breakfast meals on glucose tolerance at lunch in healthy subjects. Am J Clin Nutr 1999; 69: 647-55.

10. Axelsen M, Lönnroth P, Arvidsson Lenner R, Smith U. Suppression of nocturnal free fatty acid levels by bedtime cornstarch in NIDDM subjects. Eur J Clin Invest 1997; 27: 157-63.

11. Axelsen M, Arvidsson Lenner R, Lönnroth P, Smith U. Breakfast glycaemic response in patients with type 2 diabetes: Effects of bedtime dietary carbohydrates. Eur J Clin Nutr 1999; 53: 706-10.

12. Foster-Powell K, Holt SHA, Brand-Miller JC. International table of glycemic index and glycemic load values: 2002. Am J Clin Nutr 2002; 76: 5-56.

13. Björck IME, Liljeberg HGM, Östman EM. Low glycaemic-index foods. Br J Nutr 2000; 83(Suppl.1): S149-55.

14. Salmeron J, Ascherio A, Rimm EB, Colditz GA, Spiegelman D, Jenkins DJ, et al. Dietary fiber, glycemic load, and risk of NIDDM in men. Diabetes Care 1997; 20: 545-50.

15. Salmeron J, Manson JE, Stampfer MJ, Colditz GA, Wing AL, Willett WC. Dietary fiber, glycemic load, and risk of non-insulin-dependent diabetes mellitus in women. JAMA 1997; 277: 472-7.

16. Wolever TMS, Jenkins DJA. The use of glycemic index in predicting the blood glucose response to mixed meals. Am J Clin Nutr 1986; 43: 167-72.

17. Järvi AE, Karlström BE, Granfeldt YE, Björck IME, Asp N-G, Vessby BOH. Improved glycemic control and lipid profile and normalized fibrinolytic activity on a low glycemic index diet in type 2 diabetic patients. Diabetes Care 1999; 22: 10-8.

18. Collier GR, Wolever TMS, Wong GS, Josse RG. Prediction of glycemic response to mixed meals in non-insulin-dependent diabetic subjects. Am J Clin Nutr 1986; 44: 349-52. 
19. Chew I, Brand JC, Thorburn AW, Truswell AS. Application of glycaemic index to mixed meals. Am J Clin Nutr 1988; 47: 53-6.

20. Järvi AE, Karlström BE, Granfeldt YE, Björck IME, Vessby BOH, Asp N-G. The influence of food structure on postprandial metabolism in patients with noninsulin-dependent diabetes mellitus. Am J Clin Nutr 1995; 61: 837-42.

21. Coulston AM, Hollenbeck CB, Liu GC, Williams RA, Starich GH, Mazzaferri EL. Effect of source of dietary carbohydrate on plasma glucose, insulin and gastric inhibitory polypeptide responses to test meals in subjects with non-insulin-dependent diabetes mellitus. Am J Clin Nutr 1984; 40: 965-70.

22. Hollenbeck CB, Coulston AM. The clinical utility of the glycaemic index and its application to mixed meals. Can J Physiol Pharmacol 1991; 69: 100-7.

23. Møller BK, Flint A, Pedersen D, Raben A, Tetens I, Holst JJ, et al. Prediction of glycaemic index in mixed meals. Int J Obes Relat Metab Disord 2003; 27(Suppl 1): S38.

24. Wolever TMS, Katzman-Relle L, Jenkins AL, Vuksan V, Josse RG, Jenkins DJA. Glycemic index of 102 complex carbohydrate foods in patients with diabetes. Nutr Res 1994; 14: 651-69.

25. Bornet FR, Costagliola D, Rizkalla SW, Blayo A, Fontvielle AM, Hardt MJ, et al. Insulinaemic and glycaemic indexes of six starch-rich foods taken alone and in a mixed meal by type 2 diabetics. Am J Clin Nutr 1987; 45: 588-95.

26. Hu FB, van Dam RM, Liu S. Diet and risk of type II diabetes: the roles of types of fat and carbohydrate. Diabetologia 2001; 44: 805-17.

27. Feskens EJK, Bowles CH, Kromhout D. Carbohydrate intake and body mass index in relation to the risk of glucose intolerance in an elderly population. Am J Clin Nutr 1991; 54: 136-40.

28. Meyer KA, Kushi LH, Jacobs DR Jr, Slavin J, Sellers TA, Folsom AR. Carbohydrates, dietary fiber, and incident type 2 diabetes in older women. Am J Clin Nutr 2000; 71: 921-30.

29. Hu FB, Manson JE, Stampfer MJ, Colditz G, Liu S, Solomon CG, et al. Diet, lifestyle, and the risk of type 2 diabetes mellitus in women. N Engl J Med 2001; 345: $790-7$.

30. Liu S, Willett WC, Stampfer MJ, Hu FB, Franz M, Sampson L, et al. A prospective study of dietary glycaemic load, carbohydrate intake and risk of coronary heart disease in US women. Am J Clin Nutr 2000; 71: 1455-61.

31. Liu S, Manson JE, Stampfer MJ, Holmes MD, Hu FB, Hankinson SE, et al. Dietary glycemic load assessed by food-frequency questionnaire in relation to plasma highdensity-lipoprotein cholesterol and fasting triacylglycerols in postmenopausal women. Am J Clin Nutr 2001; 73: $560-6$.

32. Frost G, Leeds AA, Dore CJ, Madeiros S, Brading S, Dornhorst A. Glycaemic index as a determinant of serum HDL-cholesterol concentration. Lancet 1999; 353: $1045-8$.
33. Ford E, Liu S. Glycemic index and serum high-density lipoprotein cholesterol concentration among US adults. Arch Intern Med 2001; 161: 572-6.

34. van Dam RM, Visscher AW, Feskens EJ, Verhoef P, Kromhout D. Dietary glycemic index in relation to metabolic risk factors and incidence iof coronary heart disease: the Zutphen Elderly study. Eur J Clin Nutr 2000; 54: 726-31.

35. Wolever TMS, Jenkins DJ, Vuksan V, Jenkins AL, Wong GS, Josse RG. Beneficial effect of low-glycemic index diet in overweight NIDDM subjects. Diabetes Care 1992; 15: 562-4.

36. Jenkins DJA, Wolever TMS, Kalmusky J, Guidici S, Giordano C, Patten R, et al. Low-glycemic index diet in hyperlipidemia: use of traditional starchy foods. Am J Clin Nutr 1987; 46: 66-71.

37. Slabber M, Bernard HC, Kuyl JM, Dannhauser A, Schall R. Effects of a low-insulin-response, energyrestricted diet on weight loss and plasma insulin concentrations in hyperinsulinemic obese females. Am J Clin Nutr 1994; 60: 48-53.

38. Wolever TMS, Mehling C. High-carbohydrate-low-glycaemic index dietary advice improves glucose disposition index in subjects with impaired glucose tolerance. $\mathrm{Br} \mathrm{J}$ Nutr 2002; 87: 477-87.

39. Brand-Miller J, Hayne S, Petocz P, Colagiuri S. Lowglycemic index diets in the management of diabetes: a meta-analysis of randomized controlled trials. Diabetes Care 2003; 26: 2261-7.

40. Sloth B, Krog-Mikkelsen I, Flint A, Tetens I, Björck I, Vinoy S, et al. A low glycemic compared to a high glycemic index diet did not decrease body weight, but lowered LDL-cholesterol after 10 wk's ad libitum intake. Am J Clin Nutr. In press.

41. Frost G, Keogh B, Smith D, Akinsanya K, Leeds A. The effect of low-glycaemic carbohydrate on insulin and glucose response in vivo and in vitro in patients with coronary heart disease. Metabolism 1996; 45: 669-72.

42. Frost G, Leeds A, Trew G, Margara R, Dornhorst A. Insulin sensitivity in women at risk of coronary heart disease and the effect of a low GI diet. Metabolism 1998; 47: 1245-51.

43. Raben A. Should obese patients be counselled to follow a low-glycaemic index diet? No Obes Rev 2002; 3: 24556.

44. Anderson GH, Woodend D. Effect of glycaemic carbohydrates on short-term satiety and food intake. Nutr Rev 2003; 61: S17-26.

45. Wolever TMS, Mehling C. Long-term effect of varying the source or amount of dietary carbohydrate on postprandial plasma glucose, insulin, triacylglycerol, and free fatty acid concentrations in subjects with impaired glucose tolerance. Am J Clin Nutr 2003; 77: 612-21.

46. Brynes AE, Mark Edwards C, Ghatei MA, Dornhorst A, Morgan LM, Bloom SR, et al. A randomised fourintervention crossover study investigating the effect of carbohydrates on daytime profiles of insulin, glucose, 
non-esterified fatty acids and triacylglycerols in middleaged men. Br J Nutr 2003; 89: 207-18.

47. Heilbronn LK, Noakes M, Clifton PM. The effect of high- and low-glycemic index energy restricted diets on plasma lipid and glucose profiles in type 2 diabetic subjects with varying glycemic control. J Am Coll Nutr 2002; 2: 120-7.

48. Pawlak DB, Ebbelling CB, Ludwig DS. Should obese patients be counselled to follow a low-glycaemic index diet? Yes. Obesity Reviews 2002; 3: 235-43.

49. WHO Technical report Series 916: Diet, nutrition and the prevention of chronic diseases. Report of a joint FAO/WHO Expert Consultation, Geneva; 2003.

50. Anon. Dietary reference intakes for energy, carbohydrates, fiber, fat, protein and amino acids (Macronutrients). 6. Dietary carbohydrates: sugars and starches. USA: The National Academy of Sciences; 2002. p. 6-16-57.

51. The Diabetes and Nutrition Study Group (DNSG) of the European Association for the Study of Diabetes (EASD), Recommendations for the nutritional management of patients with diabetes mellitus. 1999. Eur J Clin Nutr 2000; 54: 353-5.

52. Östman EM, Liljeberg Elmståhl HGM, Björck I. Inconsistency between glycemic and insulinemic responses to regular and fermented milk products. Am J Clin Nutr 2001; 74: 96-100.

53. Liljeberg Elmståhl HGM, Björck IME. Milk as a supplement to mixed meals may elevate postprandial insulinaemia. Eur J Clin Nutr 2001; 55: 994-9.

54. Thomas DE, Brotherhood JR, Brand JC. Carbohydrate feeding before exercise: effect of glycaemic index. Int $\mathbf{J}$ Sports Med 1991; 12: 180-6.
55. DeMarco HM, Sucher KP, Cisar CJ, Butterfield GE. Pre-exercise carbohydrate meals: application of glycaemic index. Med Sci Sports Exerc 1999; 31: 164-70.

56. Kirwan JP, O'Gorman DJ, Cyr-Campbell D, Campbell WW, Yarasheski KE, Evans WJ. Effects of a moderate glycaemic meal on exercise duration and substrate utilization. Med Sci Sports Exerc 2001; 33: 1517-23.

57. Thomas DE, Brotherhood JR, Miller JB. Plasma glucose levels after prolonged strenuous exercise correlate inversely with glycemic response to food consumed before exercise. Int J Sport Nutr 1994; 4: 361-73.

58. Burke LM, Claassen A, Hawley JA, Noakes TD. Carbohydrate intake during prolonged cycling minimizes effect of glycemic index of pre-exercise meal. $\mathbf{J}$ Appl Physiol 1998 Dec; 85: 2220-6.

59. Burke LM, Collier GR, Hargreaves M. Muscle glycogen storage after prolonged exercise: effect of the glycemic index of carbohydrate feedings. J Appl Physiol 1993; 75: 1019-23.

60. Burke LM, Collier GR, Davis PG, Fricker PA, Sanigorski AJ, Hargreaves M. Muscle glycogen storage after prolonged exercise: effect of the frequency of carbohydrate feedings. Am J Clin Nutr 1996; 64: 115-9.

61. National Food Administration, Vikttabell. (In Swedish). Uppsala, Sweden; 1999.

62. National Food Administration, Food Tables. Uppsala, Sweden; 2002.

Nils-Georg Asp

SNF Swedish Nutrition Foundation

Ideon Research Park

SE-223 70 Lund, Sweden

E-mail: asp@snf.ideon.se 